2014-04-03

Prejudice and effective anti-bullying intervention: Evidence from the bullying of "minorities"

\title{
Minton, Stephen
}

http://hdl.handle.net/10026.1/15679

\subsection{0/19012276.2014.928485}

Nordic Psychology

Informa UK Limited

All content in PEARL is protected by copyright law. Author manuscripts are made available in accordance with publisher policies. Please cite only the published version using the details provided on the item record or document. In the absence of an open licence (e.g. Creative Commons), permissions for further reuse of content should be sought from the publisher or author. 


\section{Prejudice and effective anti-bullying intervention: Evidence from the bullying of "minorities"}

\section{Stephen James Minton}

To cite this article: Stephen James Minton (2014) Prejudice and effective anti-bullying intervention: Evidence from the bullying of "minorities", Nordic Psychology, 66:2, 108-120, DOI: 10.1080/19012276.2014.928485

To link to this article: https://doi.org/10.1080/19012276.2014.928485

册Published online: 19 Jun 2014.

Submit your article to this journal $\pi$

LII Article views: 1046

Q View related articles $\sqsubset$

View Crossmark data $\asymp$

4 Citing articles: 5 View citing articles 지다. 


\title{
Prejudice and effective anti-bullying intervention: Evidence from the bullying of "minorities"
}

\author{
STEPHEN JAMES MINTON \\ Correspondence address: Stephen James Minton, School of Education, Trinity College Dublin, Dublin, Republic of Ireland. \\ mintonst@tcd.ie
}

\begin{abstract}
The tradition of research into school bullying, and the development of anti-bullying intervention programmes in Norway, has had a significant influence upon similar efforts being made in other countries. However, recent evaluations of the effectiveness of school-based anti-bullying interventions have revealed mixed and most often modest levels of success. This in turn has led to suggestions being made in Norway that rather than to continue support for a direct approach to the issue of school bullying, making improvements in the "learning environment" should be prioritized; however, it is argued here that there is, as yet, no body of direct evidence to directly confirm that position. Instead, it is contended that research into school bullying has been limited to the conceptualization of bullying as being purely a sub-set of aggression, and that anti-bullying intervention has been, consequently, focused largely on purely behaviour management solutions. From recent studies on specific forms of bullying of minority groups (lesbian, gay and bisexual young people, ethnic minorities, people with disabilities or special educational needs and members of alternative sub-cultures), it appears that prejudice is at least influential on specific patterns of bullying behaviour, but has not received sufficient attention in either the conceptualization of bullying or the design of programmes to prevent and counter it. Hence, rather than scaling down direct anti-bullying intervention efforts, it is suggested that subsequent research and programme design could be re-focused in order to give a greater consideration to prejudice as an underlying factor.
\end{abstract}

Keywords: prejudice, bullying, intervention, minorities, schools

School of Education, Trinity College Dublin, Dublin, Republic of Ireland 


\section{The effectiveness of anti-bullying intervention programmes}

It is true to say that the Nordic countries, and perhaps Norway most of all, has led the world in terms of influence in the field of anti-bullying research and intervention. As well as the consistent influence of Dan Olweus (a native Swede, resident in Norway since the early 1970s), of whom Minton (2011) has stated, "... it would be difficult to over-estimate the importance of Olweus' many contributions to the field of anti-bullying" (p. 23), the very titles and sub-titles of some of Norwegian expert Erling Roland's English-language chapters and research articles are instructive. Roland was able to write about the "Scandinavian research tradition" in anti-bullying research as early as 1989; a "developing tradition of research and management" in Norway in 1993 and "three national innovations in Norwegian schools in 15 years" in 2000. Ten years after the event, Mona O' Moore wrote that the European Seminar for Teachers on Bullying in Schools held in Stavanger, Norway in 1987 (see O' Moore, 1988) was "instrumental in awakening Europe to the need for research into school bullying" (O' Moore, 1997, p. 136). Delegates at the seminar attempted to facilitate research efforts into establishing the incidence and prevalence of bullying, and the development of anti-bullying intervention programmes, on their return to their home countries (Minton \& O' Moore, 2004).

Having enjoyed some success at home along those lines, 17 years later, some of those same delegates attended the "Taking Fear Out of Schools: International Policy and Research Conference on School Bullying and Violence", again, held in Stavanger. Here, attendees heard of recent legislative changes that seemingly made anti-bullying action mandatory in Norwegian schools, and they could visit schools who were implementing one of the two governmentally supported anti-bullying programmes (Munthe et al., 2005): the long-standing Olweus programme (Olweus, 1991, 1997, 2004; Olweus \& Roland, 1983) and the new "Zero" programme (Roland et al., 2010). The delegates were addressed by the then-Norwegian prime minister, who spoke with passion and insight (Bondevik, 2004), referencing the "Manifesto mot mobbing" (Roland, 2011) he had recently co-signed on behalf of the government.

It is small wonder, then, that many researchers outside of Norway (which often seemed to be at least one step ahead) have continued to look to that country as a model in their attempts to research and intervene against bullying in schools. For example, in Ireland, a programme to prevent and counter bullying in schools was developed, based on the second nationwide intervention programme implemented in Norway in 1996 (Roland \& Munthe, 1997). In 19982000, the programme was successfully piloted (O' Moore \& Minton, 2005), and subsequently, an attempt was made to implement the programme on a nationwide basis in the academic year 2004-2005 (Minton \& O' Moore, 2008), which permitted a comparison of conditions for its implementation with that of the Zero programme in Norway (Midthassel, Minton \& O' Moore, 2009, p. 747). In short, the attempt to implement a nationwide programme in Ireland was not a success (Minton \& O' Moore, 2008), and Minton (2010) argued that central/governmental support was the crucial factor - enjoyed in Norway, but missing in Ireland:

... it may be noted that in Norway, where similar expertise has been nurtured by successive national governments, substantial inroads into preventing and dealing with bullying behaviour in schools would appear to have been made .... If the lessons learnt from 20 years of anti-bullying research and practise in Ireland can similarly be translated into centrally-supported attempts to intervene nationally, then there should be grounds for great optimism in preventing and countering school bullying behaviour. (Minton, 2010, p. 148) 
Nevertheless, at the very time that Minton (2010) was encouraging those in Ireland who were interested in a model of addressing bullying to look across the North Sea, some of his Norwegian counterparts were already looking within. In a report commissioned by the Norwegian Directorate for Education and Training, based on the Student Survey in 2007, 2008 and 2009, and including ca. 260,000 7th-10th grade students, and published by the Norwegian Institute for Studies in Innovation, Research and Education (NIFU), Lødding and Vibe (2010) stated:

Bullying is not a problem that can be solved by adopting a specific programme. The prevention and discouraging of bullying is unlikely to succeed without continuous and determined efforts to improve features of schools known to have the greatest effects on bullying: finding ways to ensure that students thrive, have a good relationship with their teachers, contribute to a positive classroom climate, receive feedback and support in their work and feel they are in safe physical environment; furthermore the school needs to have its administrative affairs in order and be a secure and respected part of the local community. In short, these features of a good learning environment can help reduce bullying. (Lødding \& Vibe, 2010, p. 26)

Olweus rejected the findings of that report outright; for example, in a short article co-written with Kyrre Breivik, they attacked the NIFU researchers' logic as "untenable"; argued that the Olweus-programme had a "strong effect", pointing to international standards and replications and described the conclusion that "a [good] learning environment actually causes reduced bullying" as "pure speculation" and "absolutely impermissible and intolerable" (Olweus \& Breivik, 2011, p. 36). Olweus and Breivik (2011) are surely correct in noting the gap that exists between the evidence presented by Lødding and Vibe (2010) and the conclusions they draw from it. Lødding and Vibe appear to this author to have taken an inductive twist; their conclusions seem to be ahead of the evidence. I can find nothing in the body of evidence that supports the conclusion that "... features of a good learning environment can help reduce bullying" (Lødding \& Vibe, 2010, p. 26). Regarding this question, I believe it would be prudent, at the present time, to adopt something like an "agnostic" position. Dealing with a question of such breadth would seem to require the concerted efforts of a multi-disciplinary team. It is noteworthy that following a recent merger, the research centre at the University of Stavanger responsible for the "Zero" programme (formerly the Centre for Behavioural Research) has become the National Centre for Learning Environment and Behavioural Research (since 1 January 2013) and seems well-placed to provide the evidence-based contributions to the question as to whether improved learning environments can reduce bullying.

To me, what the material that Lødding and Vibe (2010) reviewed does confirm is that the levels of success recorded after the implementation of some anti-bullying programmes have actually been rather modest. Olweus himself has recorded reduction rates in reports of having been bullied and having bullied of others of up to $50 \%$ following implementations of his anti-bullying programme in Bergen and Oslo (see Olweus, 2004). An evaluation of the "Zero" programme, as it was conducted in the school year 2003-2004 at 151 participating primary schools in Norway ( $n=20,430$ students), showed a statistically significant reduction in reports of having been bullied and having bullied amongst fifth to seventh grade students, but not amongst second to fourth graders in the sample (Roland et al., 2010). Additionally, an evaluation of the "Respekt" programme (broadly based, in as much as the reduction of bullying is targeted, along with other types of problematic behaviour in schools) showed "small to moderate" effect sizes "for most grade levels" (Ertesvåg \& Vaaland, 2007, p. 713). 
Internationally, Farrington and Ttofi's (2009) meta-analysis of 44 anti-bullying programmes (where it was possible to calculate effect sizes) conducted between 1983 and 2009 showed that school-based programmes succeeded in reducing bullying by between $20 \%$ and $23 \%$, and victimization by between $17 \%$ and $20 \%$. Following their meta-analysis of anti-bullying intervention research (1980-2004), Merrell et al. (2008) concluded that anti-bullying intervention programmes may produce modest positive outcomes, but that they are more likely to influence knowledge, attitudes and self-perceptions, rather than actual bullying behaviours.

In short, it is valid to conclude from the research literature that A (anti-bullying programmes) has a limited effect on $B$ (the incidence of bullying behaviour); but the leap to assuming that $C$ (improvements in the learning environment) would have a greater effect on $B$ is not. Olweus and Breivik's (2011, p. 36) question, "Where is the logic?" seems appropriate. My own contention is that the balance of evidence supports the argument of making improvements to anti-bullying programmes, rather than withdrawing them. I would like to insert a different " $\mathrm{C}$ " (the role of prejudice) as a modifier of " $\mathrm{A}$ ", rather than the suggested substitution for " $\mathrm{A}$ " that Lødding and Vibe's (2010) "learning environment" " $C$ " seems to be. The evidence-basis for my suggestion rests on the finding, which I shall document below, that certain groups of people (notably, those belonging to so-called "minority" groups) are more "at risk" of being bullied than others. Therefore, it is likely that prejudice at least exerts an influence on specific patterns of bullying behaviour (Minton, 2012).

\section{Conceptualizing bullying behaviour and the "general" whole-school approach}

A typical definition of bullying behaviour is "... long-standing violence, mental or physical, conducted by an individual or a group against an individual who is not able to defend himself or herself in that actual situation" (Roland, 1989; in Mellor, 1999). Bullying is thereby characterized as involving repetition ("a person is being bullied when he or she is exposed, repeatedly and over time, to negative interactions on the part of one or more other persons" (Olweus, 1991, p. 413; italics mine)) and a power imbalance that favours the perpetrator(s) over the target(s) ("aggressive behaviour may involve conflict between equals, whereas bullying always involves hurting someone who is not quite able to defend himself/herself" (Roland \& Idsøe, 2001, p. 446; italics mine)). Bullying has been, therefore, invariably and solely conceptualized as a sub-type of the more general category of aggressive behaviour. Indeed, Olweus (1999) provides a Venn diagram to illustrate the relationships between aggression, bullying and violence; in it, both $\mathrm{V}$ and $B$ are sub-sets of $A$, and $B \cap V$ represents "bullying with physical (violent) means" (p. 13).

In Norway, in terms of anti-bullying programme development, what has emerged from what I would argue is a limited conceptualization of bullying is a focus that is consequently limited to a sophisticated strategy of behaviour management. The Swedish researcher Anatol Pikas conceptualized bullying as a group process in the 1970s (Hareide, 2004); this emphasis has been retained in Christina Salmivalli's fruitful "participant roles" approach in understanding the group dynamics of situations of bullying behaviour (Salmivalli et al., 1996), which has been related to children's sociometric status (Björkqvist \& Österman, 1999; Salmivalli, Huttunen \& Lagerspetz, 1997) and forms the theoretical basis of Finland's nationwide anti-bullying programme, KiVa 
(Salmivalli, Kärnä \& Poskiparta, 2010). However, the understanding of bullying in Norway has been heavily weighted towards the psychological/individualistic (Hareide, 2004); the insights into bullying behaviour that have been provided (other than intervention programme development) are focused upon the internal and behavioural characteristics of those involved in bully/victim problems (Olweus, 1973, 1993, 1999, 2003) including proactive aggression in perpetrators (Roland \& Idsøe, 2001) and reactive aggression (Roland \& Idsøe, 2001) and depressive symptom formation in targets of bullying (Roland, 2002). Hareide (2004) contends that in this sense, the "problem" in Olweus' and Roland's individualized understanding is the perpetrator of the bullying; quite simply, neither has formulated variables by which the social understanding/environment can be measured.

For example, the general prerequisite for the Olweus Anti-Bullying Programme (which saw its first nationwide implementation in 1983) is awareness and involvement on the part of adults. Core programme measures at the school level are a questionnaire survey, a school conference day and better supervision during break periods; at the class level, class rules against bullying and regular class meetings with students and at the individual level, serious talks with involved students and their parents. Highly desirable measures are the formation of a co-ordinating group at the school level; class parent-teacher association at the class level and teacher and parent use of imagination at the individual level (Olweus, 1999). The "Zero" programme shares these fundamentals - of what has become known as the "whole-school" emphasis, the basic intervention approaches of awareness-raising and behavioural management and the outcome study evaluation methodologies. It is distinct in its specific training models and programme resources, in emphasizing the necessity of embedding of anti-bullying principles in the school's day-to-day practice (Midthassel, Minton \& O' Moore, 2009) and in placing a greater emphasis on implementation strategies (Roland et al., 2010). In other words, in the laudable attempt to implement anti-bullying programmes on a broad scale, a highly psychological/individualistic conceptualization of bullying behaviour has been translated into highly generalized approach to intervention - a "one size fits all" approach or an assumption that by serving the general population, that one is serving specific populations too. As we will see (below) from an examination of the studies that exist on the bullying of minority populations, this assumption appears to be ill-founded.

\section{The bullying of "minority" populations}

A good deal of anti-bullying research has focused on the cyber situation in recent years: of the 43 papers on bullying that were presented at the 15th European Conference on Developmental Psychology in 2011, 15 addressed cyber-bullying. However, others have, instead, focused on specific forms or "sub-types" of bullying and the bullying of "minority" groups. Included below are exemplar studies from the areas of homophobic bullying (in Canada, Northern Ireland, the Republic of Ireland and Norway), the bullying of ethnic minorities (in Norway), disablist bullying (in Great Britain, Northern Ireland and the Republic of Ireland) and the bullying of members of alternative sub-cultures (in the Republic of Ireland). I contend that the implications of the results of these exemplar studies are instructive in the context of the present discussion.

Firstly, the available research evidence does not support the position that in addressing bullying behaviour in general, that one is simultaneously addressing the issue of homophobic 
bullying. Canadian researchers Mishna et al. (2009) have correctly stated that "the preponderance of bullying research does not address sexual orientation as a possible factor" (p. 1598). Their compatriot, Gerald Walton, asserts that, "Even though homophobia is a prominent feature of schoolyard bullying, it is also one of the most unchallenged forms of bullying" (2006, p. 13); furthermore, he argues that apparently non-targeted anti-bullying interventions in schools may be hampered by deficits of homophobia, heterosexism and heteronormativity (Walton, 2006). Interview-based studies, albeit using relatively small samples, of the experiences of young LGB (lesbian, gay and bisexual) young people in Northern Ireland by Carolan and Redmond (2003, $n=362$ ) and in the Republic of Ireland by Minton et al. (2008, $n=123$ ), showed that $44.0 \%$ and $50.0 \%$ of their samples respectively reported having been bullied at school in the last three months because of their sexual orientation. A subsequent, and larger, questionnaire and interview-based study of 1100 LGB people in Ireland showed that 58\% of the sample reported the existence of homophobic bullying in their schools, and $5 \%$ cent had actually left school early because of homophobic bullying (Mayock et al., 2009).

Hence, whilst the self-reported experiences of homophobic bullying (current and retrospective) of LGB people was known from previous surveys in Ireland (Mayock et al., 2009; Minton et al., 2008), what remained unknown there, up until recently, was the relationship between sexual orientation and bullying in the general and current school-going population. However, in May 2010, 824 fifth-year (age ca. 16-17 years) secondary school students, at nine schools covering the entire geographical area of the Republic of Ireland, completed an English language translation of a questionnaire previously used in a large-scale empirical study in Norway (Roland \& Auestad, 2009). It was found that whereas $32.9 \%$ of heterosexual males and $20.1 \%$ of heterosexual females reported having been bullied in the last couple of months, and $9.9 \%$ and $1.5 \%$, respectively, reported having been "frequently" so (that is to say, once a week or more often), $62.5 \%$ of non-heterosexual males and $66.7 \%$ of non-heterosexual females reported having been bullied in the last couple of months and $37.5 \%$ and $20.8 \%$, respectively, reported having been frequently so (Minton, 2011). Hence, because the proportion of high school students who reported having been bullied in the last three months in O' Moore, Kirkham and Smith's nationwide survey of bullying behaviour was approximately one in six, it has been concluded that the LGB population is one "at risk" in the Irish school population of being bullied (Minton et al., 2008).

Anti-bullying action in Norway over the last decade has been legally underpinned by chapter 9A of the 2003 Education Act. According to section 9A-1 of the Act, all students attending primary and secondary schools in Norway are "... entitled to a satisfactory physical and psychosocial environment conducive to health, well-being and learning", and according to section 9A-4, schools in Norway "... shall actively make continuous and systematic efforts to promote the health, environment and safety of the pupils .... Such efforts shall apply to both the physical and the psychosocial environment". Recently, the question has been raised as to whether this law works in reality for ethnic minority children. A study of nearly 17,000 people, who participated in an extensive and representative health survey conducted in 24 municipalities containing mixed Sámi and ethnic Norwegian settlements, indicated that Sámi children experience bullying at a far higher rate of incidence (up to ten times as frequently) than do ethnic Norwegian children (Hansen et al., 2008; Hansen, Melhus \& Lund, 2010; Hansen \& Sorlie, 2012). In October 2012, there was widespread coverage in the Norwegian media concerning the physical attack on 23-year-old Eli Anne Nystad (who is from the Sámi community 
of Karasjok). Ms Nystad was attacked a gang of young men (one of whom tried to set fire to her coat with a lighter) who had heard her accent, and the incident (which took place outside a bar in Trondheim) was recorded by security cameras. The national Anti-Racism Centre, the Norwegian Sámi Parliament, and then-Prime Minister Stoltenberg all condemned the attack, the latter reminding people that harassment based on ethnic background is illegal in Norway (Hammervik et al., 2012).

Purdy and Mc Guckin (2011) note that disablist bullying has been defined by the Northern Ireland Anti-Bullying Forum (NIABF) as "... hurtful, insulting or intimidating behaviour, related to a perceived or actual disability" (NIABF, 2010), and exemplified by Bristol City Council thus:

... the regular use, consciously or unconsciously, of offensive and discriminatory language, particularly the widespread use of terms like "idiot, spastic, moron and cretin" as generic insults or terms of abuse; verbal abuse and threats; disablist graffiti; disablist comments in the course of discussions in classroom; spreading rumours that cause a young person's impairment to be questioned, ridiculed or insulted; public ridicule, e.g., imitating an individual's manner of speech or movement, interfering with necessary equipment; disablist jokes, insults and comments; physical or sexual assault against a person or group because of their impairment; refusal to cooperate/work with someone because of their impairment or behaviour; making a disabled person feel unsafe, e.g., pushing, shoving; refusing to meet a disabled person's access needs; isolation or exclusion from social groups. (2006, p. 18; in Purdy \& Mc Guckin, 2011, pp. 9 and 10).

In British studies of the prevalence of disablist bullying, 83 from a sample of 101 children with moderate learning difficulties reported having been bullied, with almost half of the reported bullying relating to the students' learning difficulties (Norwich \& Kelly, 2004), and parents in a study by the UK National Autistic Society reported that that two in five children with autism, and almost three in five with high functioning autism, had been bullied (Tippett, Houlston \& Smith, 2010). In a study of 257 trainee teachers at Initial Teacher Education centres in Northern Ireland and the Republic of Ireland, Purdy and Mc Guckin (2011) found that whilst their participants attributed high importance to the issues of special educational needs and bullying, none of them had received any guidance at all in relation to disablist bullying as part of their Initial Teacher Education. The authors recommended "... practical, solution-focused and evidencebased courses at ITE [initial teacher education] and CPD [continuing professional development] level in both jurisdictions" (p. 4).

The term "alterophobia", which may be defined as "prejudice directed towards members of alternative sub-cultures" (Minton, 2012), is a neologism modelled after the term "homophobia". It has no entry in the Oxford English Dictionary; a Google search of the Web on "alterophobia" conducted in January 2013 produced only "about 2370 results" (compared with a search on "homophobia", which produced "about 9,280,000 results"). The setting up of the "Alterophobia Blogspot", the most frequently linked-to site, was "... motivated by the death of Sophie Lancaster", a 20-year-old gap-year student who was beaten and kicked to death by a gang of drunken teenagers in a town park in Lancashire, England, in August, 2007. The attackers' murderous behaviour was apparently "provoked" by the fact that Ms Lancaster and her boyfriend (who was rendered comatose, but survived the attack) were dressed in the "gothic" fashion (Butt, 2007; Minton, 2012). The Alterophobia Blogspot (2012) asserts that

members of alternative subcultures [which the blog lists as including ... a wide range of groups, such as goths, punks, emos, skaters and fans of heavy metal] and those who listen to any type of alternative music, frequently face intolerance and even physical attacks all 
over the world .... This intolerance is based on the way they look and that their musical and other interests differ from the mainstream. Media distortion and inaccurate descriptions of subcultures usually intensify and support this prejudice.

A recent survey established that alterophobia is also evident in patterns of school bullying behaviour in Ireland. In total, 820 fifth-year students (16-17 years old; 339 male (41.3\%), 481 female $(58.7 \%)$ ), at nine secondary schools in Ireland, were asked to respond to a short, specifically constructed questionnaire (concerning membership of groups and sub-cultures and bullying behaviour). Self-identified members of sub-cultures reported both having been bullied more frequently than did members of the general sample, and participants expressed that members of "alternative" sub-cultures ("moshers/rockers", "goths" and "emos") were more likely to be bullied and that members of "non-alternative" sub-cultures ("chavs" and "D4s" (the latter of these describes an Irish liberal elitist attitude, based on the perceived opinions and characteristics of residents of Ireland's most affluent area)) were more likely to bully others. Whilst the data was admittedly exploratory in nature, it was concluded that "alterophobic bullying" was a reality in schools in Ireland and that members of "alternative" sub-cultures too may be considered to be "at risk" of being bullied in Ireland (Minton, 2012).

\section{The role of prejudice in bullying behaviour}

In each of the "minority bullying" exemplars above - homophobic bullying, the bullying of ethnic minorities, disablist bullying and alterophobic bullying - it is logical to suggest that prejudice has a strong role to play in terms of explaining why members of certain minority groups are more "at risk" of being bullied than are members of the general population. It is to be recalled that whilst tackling homophobic bullying forms part of the present programme for government in Ireland (Anti-Bullying Working Group, 2013), and that secondary schools were instructed to specifically reference homophobic bullying in their anti-bullying policies in 2010 (O' Higgins-Norman, Goldrick \& Harrison, 2010), male homosexuality was decriminalized in Ireland only in 1993 and even then the legislative reform followed only after a nine-year legal battle, including an appeal by an individual to the European Court of Human Rights (Minton, 2011). In a predominantly Roman Catholic country, educational practise has often reflected that Church's traditional teaching on homosexuality, and many participants in both Mayock et al.s (2009) and Minton et al.'s (2008) studies reported how there was a strongly discernible religiousbasis for the homophobic bullying they had suffered at school. Such country-context factors may also go some way to explaining why the prevalence rates of homophobic bullying observed in Minton's (2011) study in Ireland were significantly higher than those observed amongst young people of the same age in Norway by Roland and Auestad (2009).

Furthermore, the study of race- and ethnicity-related prejudice has a long history in the social science research literature (significantly, LaPiere, 1934), and an even longer and more extensive one in human history. It is unsurprising that the aforementioned studies indicating that Sámi children are more frequently the target of bullying, and the attack on Eli Anne Nystad, should resonate with Sámi people regarding the 100-year-long policy and practice of vornorsking ("Norwegianisation"), the forcible assimilation of the Sámi people into Norwegian society (for an authoritative review of this policy and its consequences in English, see Minde, 2005). Prejudice against people with disabilities, is, even if in the age of equality legislature rarely publically expressed, once again an ancient prejudice. Alterophobia, although a neologism, has historical 
precedents in prejudicial attitudes and behaviour directed towards members of counter- and sub-cultures throughout the latter half of the twentieth century and in the years since, although as Minton (2012) notes:

A substantial academic literature has been devoted to understanding and explaining the membership, activities and functions of sub-cultures .... However, whilst the popular media, and even the social scientists, have not shirked in documenting anti-social aspects of the behaviour of some members of alternative sub-cultures, precious little outside general news items exists concerning members of alternative sub-cultures as targets of aggression. (p. 88)

Hence, whilst we can legislate (and indeed, as we have seen, above, as Prime Minister Stoltenberg reminded us after the attack on Eli Anne Nystad, have legislated) against the behavioural expression of prejudice, psychologically speaking, the behavioural element is just one of three components that make up attitudes. The other two are the affective (how we feel) and cognitive (how we think) components (Maio \& Haddock, 2009). This means that provided a racist kept his prejudicial feelings and thoughts to himself, that he would never fall foul of the law - or, more importantly, that we cannot defeat prejudicial attitudes through legislation alone. Nevertheless, it is fairly clear that the influencing of feelings and thoughts falls within the possibilities for educational systems and school-based intervention programmes.

With this in mind, I should now like to offer two examples of how prejudice could be addressed in anti-bullying programme, which relate to two of the "minority" bullying problems that were raised above - homophobic and alterophobic bullying. In Ireland in 2010, BeLonG To (the national youth services for LGB and transgender in Ireland, for those aged 14-23 years) launched its first annual "Stand Up! LGBT Awareness Week", which is aimed at creating positive understanding of LGBT young people and their issues, with a focus on homophobia, transphobia and exclusion in schools, youth clubs and local areas and tackling homophobic and transphobic bullying (BeLonG To, 2012). The short (ca. four minutes) film that was produced to accompany Stand Up! in 2011 has received over 1.1 million hits on You Tube to date. Stand Up! has been internationally recognized by as a model of good practice by UNESCO (2012) and is to be centrally supported from the academic year 2013-2014 in the Irish government's new Action Plan on Bullying (Anti-Bullying Working Group, 2013).

In the UK, the Sophie Lancaster Foundation has developed an educational resource game, which has already been in schools, colleges, youth clubs and young offenders' institutions. The "game" is a student-focused strategy involving social cognitive training, and may be used with UK school year seven students (ca. 12 years old) and above. Specifically, it consists of 30 cards, which represent many common ethnic, religious and social groups and subcultures; players are set a series of tasks, which challenge preconceptions and encourage the development of problem solving and team working skills. The game runs over two class sessions, allowing sufficient time for discussion. Young people are helped to think about their reactions to other people, and to understand different sorts of people and groups - in other words, it teaches them about prejudice and tolerance (Sophie Lancaster Foundation, 2014). In the summer of 2011, the Sophie Lancaster Foundation completed the first of its series of one-day training courses for teachers, youth workers and other professionals which licensed them to deliver the S.O.P.H.I.E. game. In the autumn of 2012, personnel from Northern Ireland and Republic of Ireland were similarly trained, and an evaluation of the effects of their subsequent work in schools is in preparation (lorras le Chéile, 2014). It is, of course, quite possible to imagine how 
such a resource - which facilitates young people's active engagement in discussing the factors that can underlie bullying, instead of merely "raising an awareness" which, by and large, they already possess - could be included within a "whole school" intervention programme.

\section{Conclusions}

From the consideration of the studies of the bullying of "minority" populations, then, it can be said that prejudice is at the very least influential on specific patterns of bullying behaviour. It has also been shown that in how bullying behaviour has been traditionally conceptualized by researchers, and consequently, in how anti-bullying intervention programmes have been designed and focused, the role of prejudice has not received a great deal of (or even sufficient) attention. It is noted, too, that evaluations of existing school-based anti-bullying intervention programmes have shown mixed or modest levels of success. However, there is no wish to get ahead of the evidence, as Olweus and Breivik (2011) and I (see above) believe that Lødding and Vibe (2010) have done, in suggesting that direct approaches to anti-bullying be scaled back in favour of a focus on making improvements to the "learning environment". I would contend, on the basis of the arguments I have outlined above, that there is rather more evidence to support an attempt to improve the design of anti-bullying intervention programmes (on the basis of an increased attention to the role of prejudice), rather than to abandon them. Whether this leads to an improvement in the effectiveness of general anti-bullying intervention programmes themselves, of course, only time will tell; but sufficient evidence already exists to show that "minority" populations are not being served as well as they might be in current generalized approaches.

More broadly still, of course, the results from the studies of the bullying of "minorities" in themselves give cause for concern - and even more so if we extract them from the context in which they have been used here and look at them in themselves. Members of certain "minorities" are considerably more at risk of being bullied - three times or more likely if one is a homosexual teenager, rather than a heterosexual teenager in Ireland (Minton, 2011; Minton et al., 2008) and up to ten times more likely if one is a Sámi child, rather than an ethnic Norwegian child in Norway (Hansen et al., 2008; Hansen, Melhus \& Lund, 2010; Hansen \& Sorlie, 2012). Furthermore, we have seen above recent criminal cases in which young women, through the sheer misfortune of encountering gangs of drunken, prejudiced teenagers and young men, have been physically attacked (Eli Anne Nystad in Trondheim, Norway) and murdered (Sophie Lancaster in Bacup, England). On these bases, tackling prejudice is indeed a serious cause for concern. Improved legislation is always a possibility, but the very obvious existence of affective and cognitive components of all attitudes, including attitudes of prejudice, has implications for many areas of educational practice, including initial teacher training and teachers' continuing professional development. Improving the "learning environment", as Lødding and Vibe (2010) suggest, may yet prove a sensible way forward; but the evidence still points to this broad strategy necessarily involving the direct addressing of the problems of bullying and prejudice. I believe that making a contribution to jointly addressing these interlocking problems may prove possible through the improved design of school-based anti-bullying intervention programmes. 


\section{REFERENCES}

Alterophobia Blogspot (2012). Retrieved from http://www.alterophobia.blogspot.com

Anti-Bullying Working Group (2013). Action plan on bullying: Report of the anti-bullying working group to the minister for education and skills, January. Dublin: Department of Education and Skills, Department of Health and Children.

BeLOnG To (2012). BeLonG To Professional: Supporting lesbian, gay, bisexual and transgender young people in Ireland. Retrieved from http://www.belongto.org/pro

Björkqvist, K., \& Österman, K. (1999). Finland. In P. K. Smith, Y. Morita, J. Junger-Tas, D. Olweus, R. Catalano \& P. Slee (Eds.), The nature of school bullying: A cross-national perspective (pp. 56-67). London: Routledge.

Bondevik, K. M. (2004). Opening speech at the Taking Fear Out of Schools: International Policy and Research Conference on School Bullying and Violence, Stavanger, Norway, September 6. Retrieved from http://www. odin.dep.no/smk/norsk/aktuelt/taler_statsmin/taler/001001-090658/dok-bn.html

Bristol City Council Children and Young People's Services (2006). Reporting and dealing with disablist incidents in Bristol Schools. Bristol: Bristol City Council.

Butt, R. (2007). 'Tragedy beyond words' for family as woman, 20, dies after park attack. Guardian, August 25.

Carolan, F., \& Redmond, S. (2003). Shout: The needs of young people in Northern Ireland who identify as lesbian, gay, bisexual or transgender. Belfast: YouthNet.

Directorate for Primary and Secondary Education (2003). Pupils' school environment: Chapter 9a of the Education Act - Act relating to primary, lower secondary and upper secondary education. Oslo: Directorate for Primary and Secondary Education.

Ertesvåg, S. K., \& Vaaland, G. S. (2007). Prevention and reduction of behavioural problems in school: An evaluation of the Respect program. Educational Psychology, 27(6), 713-736. doi:10.1080/ 01443410701309258.

European Society for Developmental Psychology (2011). European conference on developmental psychology, 23-27 August 2011, Program Book. Bergen: University of Bergen/European Society for Developmental Psychology.

Farrington, D. P., \& Ttofi, M. M. (2009). School-based programs to reduce bullying and victimization. Oslo: Campbell Systematic Reviews.

Hammervik, M., Sande, A., Norvang, E. R., \& Ballovara, M. (2012). Her setter han fyr på Eli Anne. NRK, October 8.

Hansen, K. L., Melhus, M., Høgmo, A., \& Lund, E. (2008). Ethnic discrimination and bullying in the Sami and non-Sami populations in Norway: The SAMINOR study. International Journal of Circumpolar Health, 67, 97-113.

Hansen, K. L., Melhus, M., \& Lund, E. (2010). Ethnicity, self-reported health, discrimination and socio-economic status: A study of Sami and non-Sami Norwegian populations. International Journal of Circumpolar Health $69,111-128$.

Hansen, K. L., \& Sorlie, T. (2012). Ethnic discrimination and psychological distress: A study of Sami and nonSami populations in Norway. Transcultural Psychiatry, 49, 26-50.

Hareide, D. (2004). En kritisk beretning om «Den store nordiske mobbekrigen». Skolepsykologi, 6, 17-40.

Iorras le Chéile (2014). The S.O.P.H.I.E. foundation. Retrieved from http://www.iorraslecheile.ie/sophie_fou ndation.html

LaPiere, R. T. (1934). Attitudes vs. actions. Social Forces, 13(2), 230-237.

Lødding, B., \& Vibe, N. (2010). «Hvis noen forteller om mobbing ...» Utdypende undersøkelse av funn $i$ Elevundersøkelsen om mobbing, urettferdig behandling og diskriminering. Rapport 48/2010. Oslo: NIFU.

Maio, G. R., \& Haddock, G. (2009). The psychology of attitudes and attitude change. London: Sage.

Mayock, P., Bryan, A., Carr, N., \& Kitching, K. (2009). Supporting LGBT lives: A study of the mental health and well-being of lesbian, gay, bisexual and transgender people. Dublin: GLEN and BeLonG To.

Mellor, A. (1999). Scotland. In P. K. Smith, Y. Morita, J. Junger-Tas, D. Olweus, R. F. Catalano \& P. Slee (Eds.), The nature of school bullying: A cross-national perspective (pp. 91-111). London: Routledge.

Merrell, K. W., Gueldner, B. A., Ross, S. W., \& Isava, D. M. (2008). How effective are school bullying intervention programs? A meta-analysis of intervention research. School Psychology Quarterly, 23(1), 26-42. doi:10. 1037/1045-3830.23.1.26.

Midthassel, U. V., Minton, S. J., \& O' Moore, A. M. (2009). Conditions for the implementation of anti-bullying programmes in Norway and Ireland: A comparison of contexts and strategies. Compare: A Journal of Comparative and International Education, 39(6), 737-750. doi:10.1080/03057920902772081.

Minde, H. (2005). Assimilation of the Sámi - Implementation and consequences. Journal of Indigenous Peoples' Rights, 3, 1-33. 
Minton, S. J. (2010). Students' experiences of aggressive behaviour and bully/victim problems in Irish schools. Irish Educational Studies, 29(2), 131-152. doi:10.1080/03323311003779035.

Minton, S. J. (2011). Conceptualising school bullying behaviour: Moving beyond an atheoretical approach. Trinity Education Papers, 1(1), 22-35.

Minton, S. J. (2012). Alterophobic bullying and pro-conformist aggression in a survey of upper secondary school students in Ireland. Journal of Aggression, Conflict and Peace Research, 4(2), 86-95. doi:10.1108/ 17596591211208292.

Minton, S. J., Dahl, T., O' Moore, A. M., \& Tuck, D. (2008). An exploratory survey of the experiences of homophobic bullying amongst lesbian, gay, bisexual and transgendered young people in Ireland. Irish Education Studies, 27(2), 177-191. doi:10.1080/03323310802021961.

Minton, S. J., \& O' Moore, A. M. (2004). A review of scientifically evaluated good practices of preventing and reducing bullying at School in the EU Member States. Project. Commissioned by the European Commission (Directorate-General Justice and Home Affairs). Retrieved from http://www.europa.eu.int/ comm./justice home/eucpn/docs/review_bullying_at_school_en.pdf

Minton, S. J., \& O' Moore, A. M. (2008). The effectiveness of a nationwide intervention programme to prevent and counter school bullying in Ireland. International Journal of Psychology and Psychological Therapy, 8(1), $1-12$.

Mishna, F., Newman, P. A., Daley, A., \& Solomon, S. (2009). Bullying of lesbian and gay youth: A qualitative investigation. British Journal of Social Work, 39(8), 1598-1614. doi:10.1093/bjsw/bcm 148.

Munthe, E., Solli, E., Ytre-Arne, E. \& Roland, E. (Eds.). (2005). A report from the conference 'Taking Fear Out of Schools'. Stavanger, Norway: University of Stavanger, Centre for Behavioural Research.

Northern Ireland Anti-Bullying Forum (2010). Is your child being bullied? Information for parents and carers of children with disabilities and/or special educational needs. Belfast: Northern Ireland Anti-Bullying Forum.

Norwich, B., \& Kelly, N. (2004). Pupils' views on inclusion: Moderate learning difficulties and bullying in mainstream and special schools. British Educational Research Journal, 30(1), 43-65. doi:10.1080/ 01411920310001629965.

O' Higgins-Norman, J., Goldrick, M., \& Harrison, K. (2010). Addressing homophobic bullying in schools. Dublin: The Equality Authority.

Olweus, D. (1973). Hackkycklingar och översittare: Forskning om skol-mobbning. Kungälv: Almqvist \& Wiksell.

Olweus, D. (1991). Bully/victim problems among school children: Basic facts and effects of a school based intervention programme. In D. Pepler \& K. Rubin (Eds.), The development and treatment of childhood aggression (pp. 411-438). Hillsdale, NJ: Lawrence Earlbaum Associates.

Olweus, D. (1993). Bullying at school: What we know and what we can do. Oxford: Blackwell.

Olweus, D. (1997). Bully/victim problems in school: Knowledge base and an effective intervention program. Irish Journal of Psychology, 18(2), 170-190.

Olweus, D. (1999). Sweden, Norway. In P. K. Smith, Y. Morita, J. Junger-Tas, D. Olweus, R. F. Catalano \& P. Slee (Eds.), The nature of school bullying: A cross-national perspective (pp. 7-48). London: Routledge.

Olweus, D. (2003, March), A profile of bullying at school. Educational Leadership, 12-17.

Olweus, D. (2004). The Olweus Bullying Prevention Programme: design and implementation issues and a new national initiative in Norway. In P. K. Smith, D. Pepler \& K. Rigby (Eds.), Bullying in schools: How successful can interventions be? Cambridge: University Press Cambridge.

Olweus, D., \& Breivik, K. (2011). Mobbing, læringsmiljø og Olweus-programmet. Utdanning, 8(20), 36.

Olweus, D., \& Roland, E. (1983). Mobbing. Oslo: Kirke- og Undervisnings Departmentet.

O' Moore, A. M. (1988). Bullying in schools. Report on European teachers' seminar. Strasbourg: European Council for Co-Operation.

O' Moore, A. M. (1997). Foreword: Bullying behaviour in schools. Irish Journal of Psychology, 18(2), $135-137$.

O' Moore, A. M., \& Minton, S. J. (2005). An evaluation of the effectiveness of an anti-bullying programme in primary schools. Aggressive Behaviour, 31(6), 609-622. doi:10.1002/ab.20098.

Purdy, N., \& Mc Guckin, C. (2011). Disablist bullying: An investigation of student teachers' knowledge and confidence. Dublin: Standing Conference on Teacher Education North and South (ScoTENS).

Roland, E. (1989). Bullying: The Scandinavian research tradition. In D. P. Tattum \& D. Lane (Eds.), Bullying in schools. Stoke-on-Trent: Trentham Books.

Roland, E. (1993). Bullying: A developing tradition of research and management. In D. P. Tattum (Ed.), Understanding and managing bullying (pp. 15-30). Oxford: Heinemann Educational Books.

Roland, E. (2000). Bullying in school: Three national innovations in Norwegian schools in 15 years. Aggressive Behaviour, 26(1), 135-143. doi:10.1002/(SICI)1098-2337. 
Roland, E. (2002). Bullying, depressive symptoms and suicidal thoughts. Educational Research, 44, $55-67$. doi:10.1080/00131880110107351.

Roland, E. (2011). The broken curve: Effects of the Norwegian manifesto against bullying. International Journal of Behavioral Development, 35(5), 383-388.

Roland, E., \& Auestad, G. (2009). Seksuell orienteering og mobbing. Stavanger, Norway: University of Stavanger, Centre for Behavioural Research (internal report).

Roland, E., Bru, E., Midthassel, U. V., \& Vaaland, G. S. (2010). The Zero programme against bullying: Effects of the programme in the context of the Norwegian manifesto against bullying. Social Psychology of Education, 13, 41-55. doi:10.1007/s11218-009-9096-0.

Roland, E., \& Idsøe, T. (2001). Aggression and bullying. Aggressive Behaviour, 27(6), 446-461. doi:10.1002/ab. 1029.

Roland, E., \& Munthe, E. (1997). The 1996 Norwegian programme for preventing and managing bullying in schools. Irish Journal of Psychology, 18(2), 233-247. doi:10.1080/03033910.1997.10558142.

Salmivalli, C., Huttunen, A., \& Lagerspetz, K. M. J. (1997). Peer networks and bullying in schools. Scandinavian Journal of Psychology, 38, 305-312. doi:10.1111/1467-9450.00040.

Salmivalli, C., Kärnä, A., \& Poskiparta, E. (2010). Development, evaluation, and diffusion of a national antibullying program, KiVa. In B. Doll, W. Pfohl \& J. Yoon (Eds.), Handbook of youth prevention science (pp. 238-252). New York: Routledge.

Salmivalli, C., Lagerspetz, K., Björkqvist, K., Österman, K., \& Kaukiainen, A. (1996). Bullying as a group process: Participant roles and their relations to social status within the group. Aggressive Behaviour, 22, 1-15. doi:10.1002/(SICI)1098-2337.

Sophie Lancaster Foundation (2014). The Sophie Lancaster Foundation educational game for schools, youth groups and other young people's organisations. Retrieved from http://www.sophielancasterfoundation. com

Tippett, N., Houlston, C., \& Smith, P. K. (2010). Prevention and response to identity-based bullying among local authorities in England, Scotland and Wales. Manchester: Equality and Human Rights Commission.

UNESCO (2012). Education sector responses to homophobic bullying. Paris: UNESCO.

Walton, G. (2006). H-cubed: A primer on bullying and sexuality diversity for educators. Professional Development Perspectives, 6, 13-20. 